\section{High Relative Humidity Reduces Anther Dehiscence in Apricot, Peach, and Almond}

\author{
Thomas M. Gradziel ${ }^{1}$ and Steven A. Weinbaum \\ Department of Pomology, University of California, Davis, CA 95616 \\ Additional index words. Prunus armeniaca, P. persica, P. dulcis, pollination, fruit set, \\ breeding, cleistogamy, autogamy
}

\begin{abstract}
The regulation of anther dehiscence by relative humidity (RH) was assessed for detached anthers and detached whole flowers from a limited selection of apricot (Prunus armeniaca L.), peach [P. persica (L.) Batsch], and almond [P. dulcis (Mill.) D.A. Webb, syn. $P$. amygdalus Batsch; $P$. communis (L.) Arcangeli, non Huds.] genotypes, as well as an almond $X$ peach $F_{2}$ progeny. Dehiscence was evaluated at 33, 64, 87, 93 and $97 \% \mathrm{RH}$ for detached anthers, and at 33, 64 and $97 \%$ RH for whole detached flowers. Anther dehiscence was suppressed with increasing RH for all genotypes. Apricot anthers showed the greatest dehiscence at low RH and measurable dehiscence at high RH even when detached. Anther dehiscence in almond appeared more suppressed than in apricot at all RH levels tested, being completely suppressed by high RH in detached anthers. Peach genotypes exhibited the full range of variability between apricot and almond patterns. Evidence for transgressive segregation of RH-controlled anther dehiscence was observed in the occurrence of cleistogamy in an almond $x$ peach $F_{2}$ progeny. Rates of anther dehiscence were approximately linear with change in $\mathrm{RH}$ in detached anthers but exhibited a more buffered, step-wise response when detached whole flowers were tested. Results are consistent with field observations, and highlight the low but measurable risk of cleistogamy in these species, as well as opportunities to modify the breeding systems and crossing environments to facilitate controlled hybridization, and to reduce pollination vulnerability to adverse environments.
\end{abstract}

Apricot, peach, and almond are among the earliest flowering of the economically important temperate tree fruit crops. Flowering in California occurs during the end of the winter storm season, and weather conditions during bloom are a major determinant of final crop size (Hesse, 1975; Kester and Gradziel, 1996). Rain during bloom remains the most serious threat to fruit set due to its promotion of floral disease and its suppression of self- and crosspollination. Pollination failures can also result from the excessive hydration and rupture of pollen grains when exposed to free water, and from the suppression of anther dehiscence by high RH (Corbet, 1990). While the effects of water content on pollen hydration and germination have been well characterized (Bassani et al., 1994; Gilissen, 1977; Heslop-Harrison, 1979), few studies have examined the influence of differing $\mathrm{RH}$ on anther dehiscence for crop species. In pecan [Carya illinoinensis (Wang.) K. Koch (syn. C. illinoensis auct.)], an anemophilous species with a heterodichogamous flowering habit, increasing RH suppressed anther dehiscence, although this influence could be reduced by increasing temperatures (Yates and Sparks, 1993). Very

Received for publication 20 July 1998 . Accepted for publication 17 Nov. 1998. The cost of publishing this paper was defrayed in part by the payment of page charges. Under postal regulations, this paper therefore must be hereby marked advertisement solely to indicate this fact.

${ }^{1}$ To whom reprint requests should be addressed. high RH generally suppresses anther dehiscence in peach and almond (Hesse, 1975). Layne et al. (1996) warned that apricot flower buds harvested for subsequent pollen collection need to be stored at low temperatures to suppress anther dehiscence even at the high internal RH of the closed flower bud at balloon or popcorn stage. Such pre-anthesis cleistogamy (Lord, 1981), while rarely observed in our breeding work in almond, has occasionally been observed in peach and in progeny from interspecific peach $\mathrm{x}$ almond crosses. Self-pollination associated with undetected cleistogamy could confound breeding progress and genetic studies (Frankel and Galun, 1977). Cleistogamous pollination, however, could protect generative organs from inclement weather and disease (Corbet, 1990). Similarly, the use of high RH to suppress anther dehiscence of otherwise open and receptive flowers would achieve a functional self-sterility that could be exploited to effect hybridization without the tedium and damage associated with physical emasculation. Genetic differences in the dehiscence response of anthers to RH have been reported in pecan (Yates and Sparks, 1993) and several noncommercial species (Corbet, 1990). The goal of this study was to assess the influence of both Prunus genotype and RH on anther dehiscence.

\section{Materials and Methods}

Plant material. Four genotypes of peach and two each of apricot, almond, and an almond $\mathrm{X}$ peach $\mathrm{F}_{2}$ were selected for their range of flowering types and breeding habits (Table 1). Flowers at the white-tip (apricot) or pinkbud stage of development (almond and peach) (IPM Manual Group, 1985) were harvested from mature trees growing under standard commercial conditions at the Wolfskill Experimental Orchards in Winters, Calif.

Effect of RH on dehiscence of detached anthers. Flowers were harvested in February and March of 1989 and transported to the laboratory. For each test, at least 10 undamaged and normal-looking anthers were harvested from flowers of each genotype. Individual anthers were detached at the filament base from the hypanthium or floral tube and placed immediately with other anthers of that genotype in a small vial of distilled water so that the anther sac extended several millimeters above the top of the vial. A tray containing all selections was placed in each of five clear plastic boxes, each having a different $\mathrm{RH}$ and maintained at a constant temperature of $25^{\circ} \mathrm{C}$. Relative humidity was standardized using saturated salt solutions [33\% with $\mathrm{MgCl}_{2}, 64 \%$ with $\mathrm{NaNO}_{3}, 87 \%$ with $\mathrm{K}_{2} \mathrm{CrO}_{4}, 93 \%$ with $\left(\mathrm{NH}_{4}\right) \mathrm{H}_{2} \mathrm{PO}_{4}$, and $97 \%$ with $\mathrm{CuSO}_{4}$ ] as recommended by Young (1967) and verified using a LI-COR model 1600 steady-state pyrometer (LI-COR, Lincoln, Nebr.). The proportion of dehiscent anthers for each selection and RH was recorded after $0,2,4,9,18,30,42,48$, and $70 \mathrm{~h}$. Anthers were scored as dehiscent when the anther suture split and individual pollen grains could be observed at or outside the suture split.

Effect of RH on dehiscence of anthers on detached whole flowers. For each test, at least 10 whole normal-appearing flower buds of

Table 1. Prunus selections evaluated and their flower characteristics

\begin{tabular}{lllcr}
\hline \hline Species & Genotype & Flower-type & Self-compatibility & Bloom date $^{z}$ \\
\hline Apricot & Royal & Nonshowy & Yes & 10 \\
& Patterson & Nonshowy & Yes & 12 \\
Peach & Fay Elberta & Showy & Yes & 17 \\
& Carson & Showy & Yes & 20 \\
& Dr. Davis & Nonshowy & Yes & 16 \\
& Flamecrest & Showy & Yes & 18 \\
Almond & Mission & Showy & No & 7 \\
& Nonpareil & Showy & No & 0 \\
$(\mathrm{~A} \times \mathrm{P}) \mathrm{F}_{2}{ }^{\mathrm{y}}$ & A x P1 & Showy & No & 3 \\
& A x P2 & Showy & Yes & 10 \\
\hline
\end{tabular}

${ }^{2}$ Days after bloom initiation in 'Nonpareil' almond.

${ }^{\mathrm{y}} \mathrm{F}_{2}$ progeny of an almond $\mathrm{x}$ peach interspecific hybrid. 


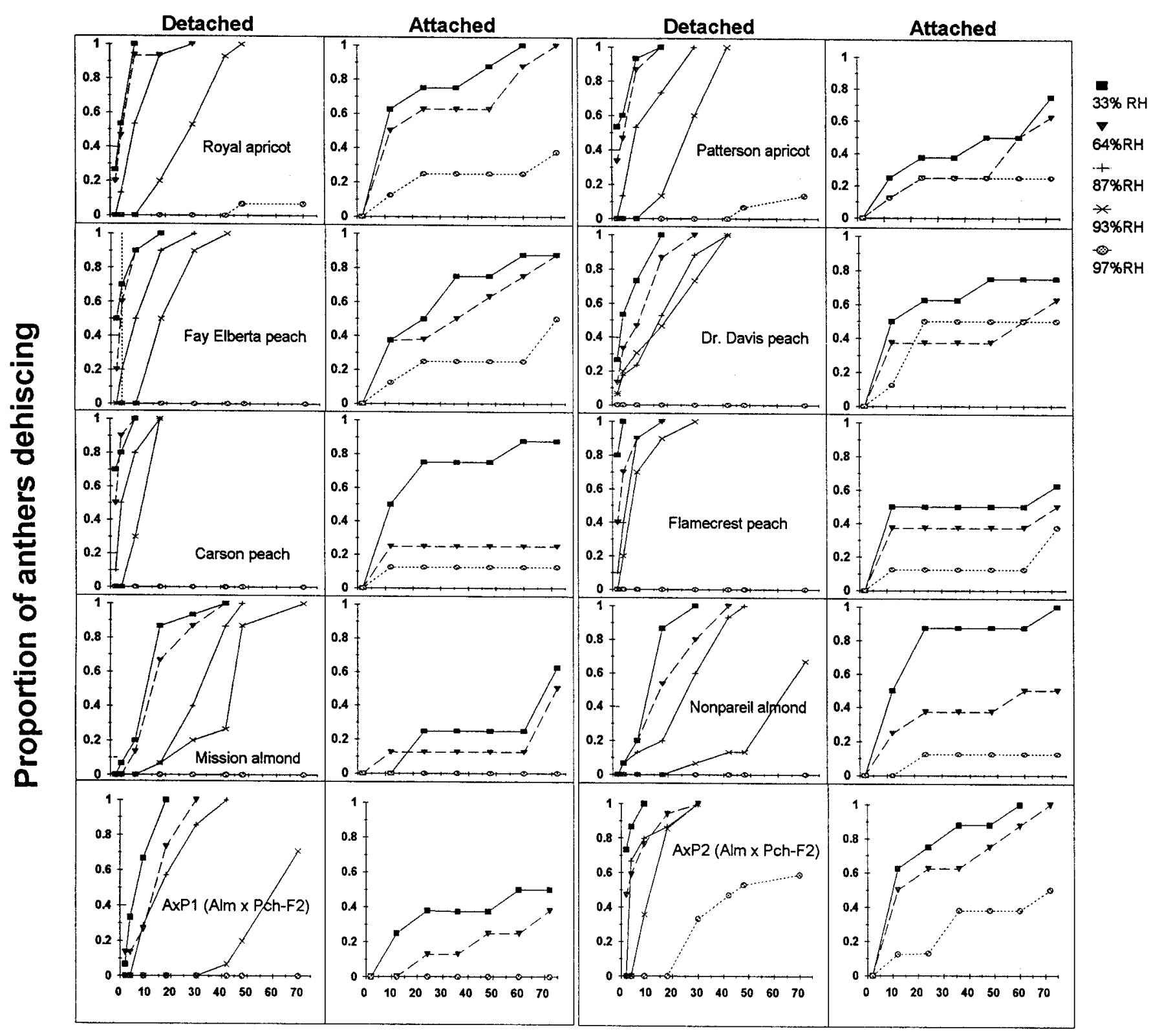

Time to dehiscence $(h)$

Fig. 1. Effect of RH on time to anther dehiscence in detached anthers (detached) and those attached to entire detached flowers (attached).

each selection were collected in 1995 at the white-tip (apricot) or pink-bud stage. Each bud was placed over a 2-mL vial of distilled water, using a perforated plastic film over the top of the vial so that the pedicel was in water but the hypanthium was not. Trays containing complete samples of all selections were placed at a constant temperature of $25^{\circ} \mathrm{C}$ in clear plastic boxes at $33 \%, 64 \%$, or $97 \% \mathrm{RH}$, generated as described previously. The proportion of flowers having at least one dehiscent anther, as well as the proportion of dehiscent anthers within each flower for each selection and $\mathrm{RH}$, were recorded at $0,2,12,24,36,48,60$, and 72 h. Moldy or otherwise damaged flowers were not scored.

Statistical analysis. Data were analyzed using SAS's REG procedure (Ver. 6.11, SAS, Cary, N.C.) to evaluate the linear regression of anther dehiscence with time for each genotype and RH.

\section{Results and Discussion}

Anther dehiscence was suppressed with increasing RH (Fig. 1). The highest RH tested, $97 \%$, was most effective in suppressing dehiscence in whole flowers and almost completely suppressed dehiscence in excised anthers. Small changes in RH often resulted in distinctly different anther dehiscence patterns, as seen in the difference between 87,93 and $97 \%$ $\mathrm{RH}$ for detached anthers. Dehiscence of detached anthers was often similar at $33 \%$ and $64 \% \mathrm{RH}$, suggesting a response threshold at low RH (Fig. 1 and Table 2). Clearer differences in anther dehiscence between these lower $\mathrm{RH}$ levels were observed when whole flowers were tested (Fig. 1 and Table 3). Response curves for detached anthers were more linear than those for whole flowers which typically showed a staggered or stepped increase with time (Fig. 1 and Table 3). The first anthers to dehisce were often attached to the same petal or group of adjacent petals. The delicate tissue structure and high surface area make petals effective sensors of atmospheric moisture (Corbet, 1990; Lisci et al., 1994). Prolonged exposure to desiccating environments or damage to this tissue can lead to water loss and ultimately to desiccation of both the petal and attached anther (Frankel and Galun, 1977; Gilissen, 1976; Schmid, 1976; Stanley and Linskens, 1974). Individual petals may also act as reservoirs of moisture for the maturing anthers (Corbet, 1990; Lord, 1981). Such an integrated response in Prunus may have contributed to the step-wise increase with time in anther dehiscence in whole flowers (Fig. 1). Once anther dehiscence had begun in an individual flower, it continued at a fairly constant rate. While the rate and final proportion of dehiscence differed for each species (as summarized in Fig. 1), the general within-flower 
Table 2. Analysis of variance table for the regression of detached anther dehiscence with time for different genotypes under controlled relative humidity (RH).

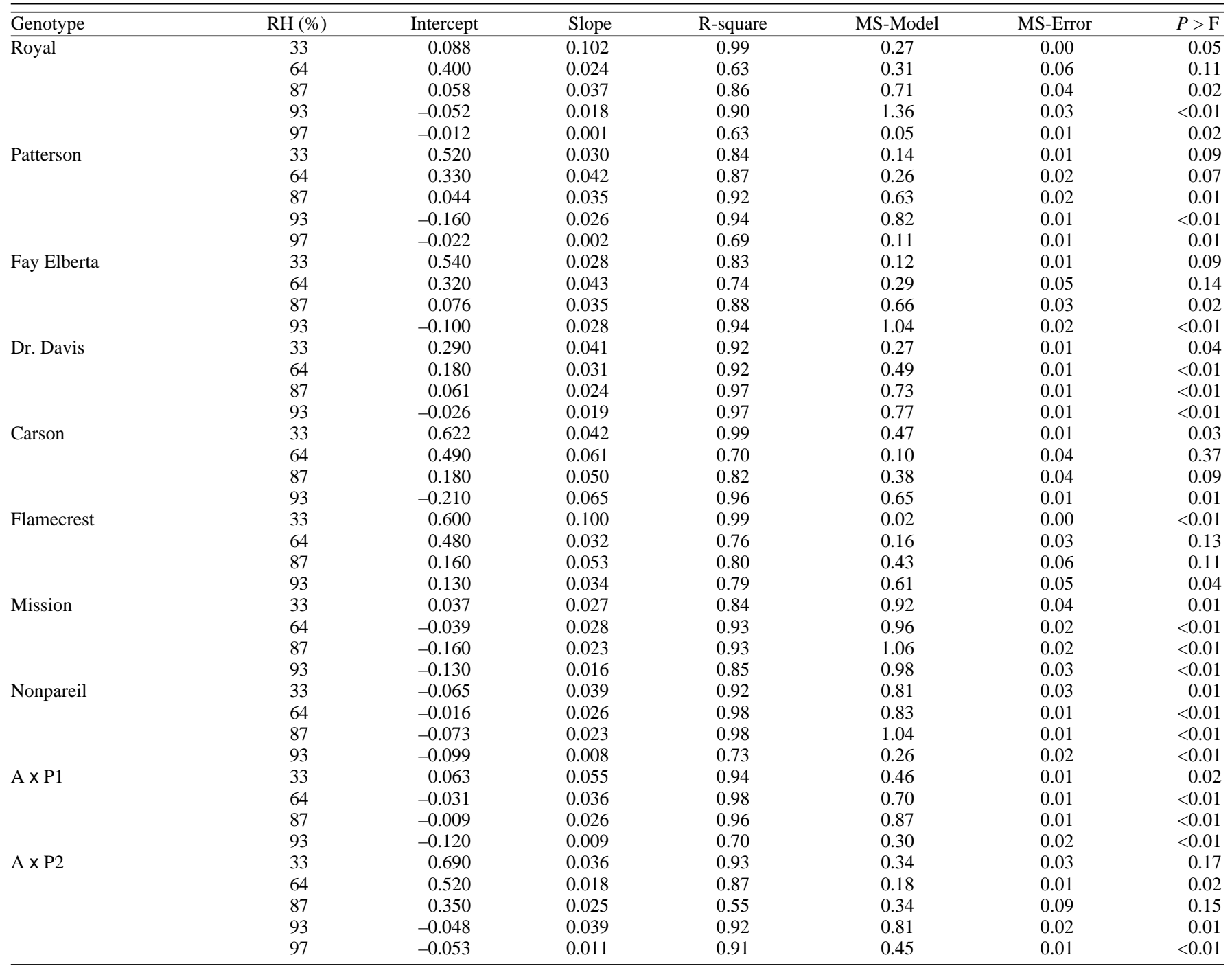

Table 3. Analysis of variance table for the regression of detached whole flower dehiscence with time for different genotypes under controlled relative humidity (RH).

\begin{tabular}{|c|c|c|c|c|c|c|c|}
\hline Genotype & RH (\%) & Intercept & Slope & $\mathrm{R}$-square & MS-Model & MS-Error & $P>\mathrm{F}$ \\
\hline \multirow[t]{3}{*}{ Royal } & 33 & 0.250 & 0.014 & 0.74 & 0.46 & 0.04 & 0.03 \\
\hline & 64 & 0.201 & 0.011 & 0.81 & 0.50 & 0.02 & $<0.01$ \\
\hline & 97 & 0.065 & 0.004 & 0.78 & 0.07 & 0.01 & $<0.01$ \\
\hline & 64 & -0.002 & 0.008 & 0.90 & 0.25 & 0.01 & $<0.01$ \\
\hline & 97 & 0.090 & 0.003 & 0.59 & 0.03 & 0.01 & 0.04 \\
\hline \multirow[t]{2}{*}{ Fay Elberta } & 33 & 0.167 & 0.012 & 0.86 & 0.53 & 0.02 & $<0.01$ \\
\hline & 64 & 0.106 & 0.011 & 0.93 & 0.47 & 0.01 & $<0.01$ \\
\hline \multirow{2}{*}{ Dr. Davis } & 64 & 0.147 & 0.006 & 0.71 & 0.16 & 0.01 & 0.02 \\
\hline & 97 & 0.132 & 0.007 & 0.63 & 0.18 & 0.02 & 0.03 \\
\hline \multirow[t]{3}{*}{ Carson } & 33 & 0.276 & 0.010 & 0.69 & 0.40 & 0.04 & 0.02 \\
\hline & 64 & 0.134 & 0.002 & 0.35 & 0.02 & 0.01 & 0.16 \\
\hline & 97 & 0.067 & 0.001 & 0.35 & 0.02 & 0.01 & 0.16 \\
\hline \multirow[t]{2}{*}{ Flamecrest } & 33 & 0.244 & 0.006 & 0.49 & 0.12 & 0.03 & 0.08 \\
\hline & 64 & 0.181 & 0.005 & 0.52 & 0.08 & 0.01 & 0.07 \\
\hline \multirow{2}{*}{ Nonpareil } & 64 & 0.124 & 0.006 & 0.78 & 0.14 & 0.01 & $<0.01$ \\
\hline & 97 & 0.022 & 0.002 & 0.62 & 0.08 & 0.01 & 0.04 \\
\hline \multirow[t]{2}{*}{ A x P1 } & 33 & 0.124 & 0.006 & 0.78 & 0.14 & 0.01 & $<0.01$ \\
\hline & 64 & -0.031 & 0.005 & 0.95 & 0.11 & 0.01 & $<0.01$ \\
\hline \multirow[t]{3}{*}{$\mathrm{A} \times \mathrm{P} 2$} & 33 & 0.262 & 0.014 & 0.73 & 0.48 & 0.04 & 0.03 \\
\hline & 64 & 0.205 & 0.012 & 0.84 & 0.53 & 0.02 & $<0.01$ \\
\hline & 97 & 0.025 & 0.007 & 0.89 & 0.18 & 0.01 & $<0.01$ \\
\hline
\end{tabular}


pattern was similar for all selections tested. Differences in desiccation rates among individual flowers in the same test may have resulted from more subtle differences in the structure and composition (thin cuticle, disorganized epidermal cells, stomata, etc.) of anthers, anther filaments and petals (Corbet, 1990; Frankel and Galun, 1977; Gilissen, 1976; Schmid, 1976; Stanley and Linskens, 1974).

Between- and within-species differences for anther dehiscence rates at tested RHs (Fig. 1 , Tables 2 and 3 ) suggest important genetic influences on this process. Apricot was distinguished from the other species by a rapid anther dehiscence at low $\mathrm{RH}$ and measurable dehiscence at $97 \% \mathrm{RH}$, even for detached anthers (Fig. 1). Similar responses were observed in the apricot 'Tilton' and several seedling selections tested (data not shown), in agreement with the observation of Layne et al. (1996) that apricot anthers in detached flowers will sometimes dehisce in the buds at typical field temperatures. Almond was distinguished from peach and apricot by its delayed anther dehiscence at low RH and suppressed anther dehiscence at very high RH. This pattern was also seen in progeny from 'Nonpareil' $x$ 'Mission' crosses (data not shown). Peach, however, showed the full range of variability between these responses. The lowest levels of anther dehiscence at $97 \% \mathrm{RH}$ were similar to those for almond, while the highest levels of anther dehiscence approached those for apricot. At $97 \%$ RH, peach anther dehiscence was completely suppressed in detached anthers but moderately variable when whole flowers were tested. 'Dr. Davis', the only nonshowy flowered peach tested, had the highest level of dehiscence at $97 \%$ RH. Many commercial processing peach cultivars possess large, almond-like, showy flower petals, rather than the smaller and more ragged nonshowy petals. Anther dehiscence in apricot, which has nonshowy flowers, was also high at $97 \% \mathrm{RH}$, although, as previously discussed, some dehiscence was also observed in detached anthers (Fig. 1). A more rapid anther dehiscence in nonshowy flowers may be a result of the more open architecture of such flowers or the lower moisture reserves in the smaller petals as proposed for other species by Corbet (1990) and Frankel and Galun (1977). We had previously observed that anther dehiscence in showy-flowered peach selections in the field was totally suppressed at RH near $100 \%$. We have exploited this behavior to make outcrosses to these genotypes without emasculation. Branches or whole trees were enclosed and internal humidities allowed to approach $100 \%$, but without allowing noticeable water condensation on the flowers or stems. When flowers were fully opened, the enclosure was removed and cross-pollen applied before anthers of the seed parent dehisced. Subsequent seed were screened for accidental selfs using genetic markers, usually the ee (eglandular leaf) gene as described by Scorza and Sherman (1996). Results have been inconsistent, however, possibly because excessive moisture on the stigma of treated flowers resulted in bursting of the applied pollen grains (Bassani et al., 1994; Heslop-Harrison, 1979; Konar and Linskens, 1966).

Almond, which had showy, self-incompatible flowers, bloomed in mid- to late February in 1995 in California when rains were frequent and daytime temperatures averaged $18.3^{\circ} \mathrm{C}$. The apricots tested, which had relatively small, nonshowy and self-compatible to partially selfincompatible flowers (Layne et al., 1996), bloomed just after almond. The self-compatible peach bloomed during early to mid-March when the threat of rain was reduced and average daytime temperatures approached $20^{\circ} \mathrm{C}$. No consistent relationship was observed between anther dehiscence and time of bloom (Table 1, Fig. 1). While the influence of field temperatures on the dehiscence of Prunus anthers has not been studied, higher temperatures would be expected to promote anther desiccation and dehiscence, as reported by Yates and Sparks (1993) in pecan, whereas lower temperatures would be expected to suppress dehiscence, as reported by Layne et al. (1996) for apricot. Such temperature effects could be important, since field temperatures from 1987 to 1997 ranged from -5.6 to $26.7^{\circ} \mathrm{C}$ in February, and from 0.6 to $33.3{ }^{\circ} \mathrm{C}$ in March.

Anther dehiscence in an $\mathrm{F}_{2}$ progeny from an almond $x$ peach interspecific cross was intermediate between the parental extremes, as demonstrated by the samples in this study (Fig. 1, Table 1). Evidence for transgressive segregation for anther dehiscence under high $\mathrm{RH}$ was evident in the high anther dehiscence of the last selection in Fig. 1 (A x P2, a vigorous peach-type tree with clingstone peach fruit). While little is known about the genetic control of anther dehiscence in Prunus species, genetic factors controlling anther sac dehiscence have now been well characterized for other crop species (Goldberg et al., 1993). A $\times$ P2 also retained the self-compatibility gene from peach. The combination of selfcompatibility and cleistogamy would allow unrecognized self-pollination, which could confound genetic studies and retard breeding progress. Indeed, dehiscent anthers have been observed in the field for this and related selections in closed, pink-tip to popcorn stage flower buds. The frequency of cleistogamy was less than $10 \%$ but still much higher than normally observed (usually $<0.1 \%$ ) in either almond or peach. Occasionally pollen could also be seen on the stigma, which is often in contact with pre-anthesis anthers because of crowding within the unopened bud. While studies to test the occurrence of cleistogamous pollen germination and fertilization have not yet been completed, earlier research by Herrero and Arbeloa (1989) indicated that the peach stigma matures well before the ovary does. Cleistogamy, while frustrating to breeding studies, might offer unique opportunities to protect these early flowering tree crops from both inclement weather (Corbet, 1990) and serious diseases such as flower blight caused by Monilinia sp., which appears to infect through exposed anther filaments (Ogawa et al., 1985).

The general suppression of anther dehiscence by RH levels typical of the near-saturated humidities found in intact, unopened flower buds make the probability of cleistogamy relatively low in peach and almond, but higher in apricot. However, the risk of such unwanted pollinations in breeding programs, the potential for employing cleistogamy to protect field pollinations from inclement weather and disease, and the opportunities for avoiding the need for emasculation in controlled crosses, argue for continued efforts towards a more detailed understanding of the genetic and environmental factors controlling this process.

\section{Literature Cited}

Bassani, M., G.G. Franchi, and E. Pacini. 1994. Humidity stress response in pollen of anemophilous and entomophilous species. Grana 33:146-150.

Corbet. S.A. 1990. Pollination and the weather. Israel J. Bot. 39:13-30

Frankel, R. and E. Galun. 1977. Pollination mechanisms, reproduction and plant breeding. Springer-Verlag, Berlin

Gilissen, L.J.W. 1976. The role of the style as a sense-organ in relation to wilting of the flower. Planta 131:201-202.

Gilissen, L.J.W. 1977. The influence of relative humidity on the swelling of pollen grains in vitro. Planta 137:299301.

Goldberg, R.B., T.P. Beals, and P.M. Sanders. 1993. Anther development: Basic principles and practical applications. Plant Cell 5:1217-1229.

Herrero, M. and A. Arbeloa. 1989. Influence of the pistil on pollen tube kinetics in peach (Prunus persica). Amer. J. Bot. 76:1441-1447.

Heslop-Harrison, J. 1979. An interpretation of the hydrodynamics of pollen. Amer. J. Bot. 66:737-743

Hesse, C.O. 1975. Peaches, p. 285-335. In: Advances in fruit breeding. J. Janick and J.N. Moore (eds.). Purdue Univ. Press, West Lafayette, Ind.

IPM Manual Group. 1985. Integrated pest management for almonds. Publ. \#3308. Univ. of California Div. of Agr. and Nat. Res., Berkeley.

Kester, D.E. and T.M. Gradziel. 1996. Almonds, p. 1-97. In: J. Janick and J.N. Moore (eds.). Fruit breeding. vol. III: Nuts. Wiley, New York.

Konar, R.N. and H.F. Linskens. 1966. Physiology and biochemistry of the stigmatic fluid of Petunia hybrida. Planta 71:372-387.

Layne, R.E.C., C.H. Bailey, and L.F. Hough. 1996. Apricots, p. 79-111. In: J. Janick and J.N. Moore (eds.). Fruit breeding. vol. I: Tree and tropical fruits. Wiley, New York.

Lisci, M., C. Tanda, and E. Pacini. 1994. Pollination ecophysiology of Mercurialis annua L. (Euphorbiaceae), an anemophilous species flowering all year round. Ann. Bot. 74:125-135.

Lord, E.M. 1981. Cleistogamy: A tool for the study of floral morphogenesis, function and evolution. Bot. Rev. 47:421-449.

Ogawa, J.M., B.T. Manji, and R.M. Sonoda. 1985. Management of the brown rot disease on stone fruits and almonds in California, p. 8-15. In: T.J. Burr (ed.). Proc. of the brown rot of stone fruit workshop. Ames, Iowa, 11 July 1983. New York State Agr. Expt. Sta., Geneva Spec. Rpt. 55.

Schmid, R. 1976. Filament histology and anther dehiscence. Bot. J. Linn. Soc. 73:303-315.

Scorza, R. and W.B. Sherman. 1996. Peaches, p. 325-440. In: J. Janick and J.N. Moore (eds.). Fruit breeding. vol. I: Tree and tropical fruits. Wiley, New York.

Stanley, R.G. and H.F. Linskens. 1974. Pollen: Biology, biochemistry, management. Springer-Verlag, Berlin.

Yates, I.E. and D. Sparks. 1993. Environmental regulation of anther dehiscence and pollen germination in pecan. J. Amer. Soc. Hort. Sci. 118:699-706.

Young, J.F. 1967. Humidity control in the laboratory using salt solutions: A review. J. Appl. Chem. 17:241-245. 